\title{
Cleavage of Type II Collagen by Cathepsin K in Human Osteoarthritic Cartilage
}

\author{
Valeria M. Dejica, ${ }^{\star}$ John S. Mort, ${ }^{*}$ Sheila Laverty, ${ }^{\dagger}$ \\ M. David Percival, ${ }^{\neq}$John Antoniou, ${ }^{\S}$ \\ David J. Zukor, ${ }^{\S}$ and A. Robin Poole* \\ From the Joint Diseases Laboratory, "Shriners Hospitals for \\ Children, Division of Surgical Research, Department of Surgery, \\ and the Jewish General Hospital, ${ }^{\S}$ McGill University, Montreal; \\ the Département de Sciences Cliniques, ${ }^{\dagger}$ Faculté de Médecine \\ Vétérinaire, Université de Montréal, St. Hyacinthe; and the \\ Department of Biochemistry and Molecular Biology, ${ }^{\ddagger}$ Merck Frosst \\ Centre for Therapeutic Research, Kirkland, Canada
}

Cathepsin $K$ is a cysteine protease of the papain family that cleaves triple-helical type II collagen, the major structural component of the extracellular matrix of articular cartilage. In osteoarthritis (OA), the anabolic/catabolic balance of articular cartilage is disrupted with the excessive cleavage of collagen II by collagenases or matrix metalloproteinases. A polyclonal antibody against a C-terminal neoepitope (C2K) generated in triple-helical type II collagen by the proteolytic action of cathepsin $K$ was prepared and used to develop an enzyme-linked immunosorbent assay to study the generation of this epitope and the effects of its presence in normal adult and osteoarthritic femoral condylar articular cartilage. The generation of the $C 2 K$ epitope in explant culture and the effect of a specific cathepsin $\mathrm{K}$ inhibitor were studied. The neoepitope, which is not generated by the collagenase matrix metalloproteinase-13, increased with age in articular cartilage and was significantly elevated in osteoarthritic cartilage compared with adult nonarthritic cartilage. Moreover, in explants from three of eight $\mathrm{OA}$ patients, the generation of the neoepitope in culture was significantly reduced by a specific, nontoxic inhibitor of cathepsin $\mathrm{K}$. These data suggest that cathepsin $K$ is involved in the cleavage of type II collagen in human articular cartilage in certain OA patients and that it may play a role in both OA pathophysiology and the aging process. (Am J Pathol 2008, 173:161-169; DOI: 10.2353/ajpath.2008.070494)

Type II collagen (Col II), the major structural component of the extracellular matrix of articular cartilage, is com- posed of three identical $\alpha$ chains that form a triple helix. These molecules self-associate to form the collagen fibrils, which are stabilized by intermolecular crosslinks. In osteoarthritis (OA), the anabolic/catabolic balance of articular cartilage is disrupted with excessive cleavage of Col II involving collagenases, which are matrix metalloproteinases or MMPs. ${ }^{1-4}$ This leads to collagen denaturation $^{5,6}$ and disruption of the collagen fibrillar network with a loss of the tensile properties of articular cartilage. ${ }^{7}$ The collagenases cleave triple helical Col II at a single site (Gly775-Leu/lle776) toward the C-terminal end, resulting in the release of ${ }^{3 / 4} \mathrm{~N}$-terminal $\left(T C^{A}\right)$ and ${ }^{1 / 4} \mathrm{C}$-terminal $\left(T C^{B}\right)$ collagen fragments. ${ }^{3,8}$

Until recently the collagenases were the only proteinases present in connective tissues known to be capable of cleaving the triple helix of Col II. Now we know that that the cysteine protease cathepsin $\mathrm{K}$ can also cleave the triple helix of types I and II collagens but at different sites to MMPs., ${ }^{9,10}$ Cathepsin $\mathrm{K}$ is also capable of degrading other matrix molecules of hyaline cartilage, such as aggrecan and link protein. ${ }^{11}$ The aggrecan-degrading activity of cathepsin $\mathrm{K}$ leads to the release of glycosaminoglycan-containing fragments that interact with the enzyme and form collagenolytically active complexes with increased stability at normal $\mathrm{pH} .{ }^{10}$ Cathepsin $\mathrm{K}$ is the only cysteine protease that has also been shown to cleave telopeptide domains as well as $\alpha$-chains of fibrillar collagens at multiple sites. ${ }^{12}$ Degradation of telopeptides leads to depolymerization of the fibrillar network, whereas cleavage of the triple helix results in depolymerization and denaturation. Identification of the primary cleavage sites generated in the triple helices of type I and II collagens shows that cathepsin $\mathrm{K}$ cleaves the $\alpha$-chains close to the $\mathrm{N}$ terminus of the triple helix located 58 residues from the $\mathrm{N}$ terminus, at a Gly-Lys bond, ${ }^{9}$ a cleavage site

Supported by the Shriners of North America (to A.R.P. and J.S.M.); the Institute of Musculoskeletal Health and Arthritis, Canadian Institutes of Health Research (to A.R.P.); and the Canadian Arthritis Network and IBEX Pharmaceuticals (joint funding of a postdoctoral fellowship to V.M.D.).

Accepted for publication March 31, 2008.

M.P. is an employee of Merck.

Address reprint requests to Valeria M. Dejica, Joint Diseases Laboratory, Shriners Hospitals for Children, 1529 Cedar Ave., Montreal, Quebec, H3G1A6, Canada. E-mail: vdejica@shriners.mcgill.ca. 
that has not been observed for other proteases. Although members of the MMP family cleave collagen at a neutral $\mathrm{pH}$, cathepsin $\mathrm{K}$ has an increased proteolytic activity in a more acidic environment. At an optimum $\mathrm{pH}$ of $\sim 6 \mathrm{ca}-$ thepsin $\mathrm{K}$ has strong collagenolytic, elastinolytic, and gelatinolytic activities. ${ }^{13}$ Recent observations have detected a reduced $\mathrm{pH}$ in $\mathrm{OA}$ cartilage that would favor cathepsin $\mathrm{K}$ activity. ${ }^{14}$ The $\mathrm{pH}$ can decrease from neutral to $\sim 5.5$ in relation to the course of the progression of cartilage degeneration in OA. In this article we describe the development and validation of a sensitive and specific immunoassay that detects and measures the cleavage of triple helical Col II by cathepsin $\mathrm{K}$ in normal and $\mathrm{OA}$ articular cartilages. The assay is based on polyclonal antibodies raised against the $\mathrm{C}$-terminal neoepitope termed C2K of the short $\alpha$-chain fragment generated by cathepsin $\mathrm{K}$ cleavage of $\mathrm{Col}$ II. The assay was used to quantify the amount of the neoepitope present in aging human nonarthritic and OA articular cartilage. Our results reveal an increased content of this neoepitope in extracts of nonarthritic cartilage from older individuals compared to that from young individuals and a further increase in $\mathrm{OA}$ cartilage. Because the generation of $\mathrm{C} 2 \mathrm{~K}$ neoepitope in explants of cultured OA articular cartilage can be inhibited by a specific nontoxic cathepsin $\mathrm{K}$ inhibitor these observations suggest that cathepsin $\mathrm{K}$ may play a role in Col II cleavage in aging and OA.

\section{Materials and Methods}

\section{Tissue}

At total knee arthroplasty full-depth human articular femoral condylar cartilages were obtained from 27 patients with knee OA diagnosed in accordance with the criteria of the American College of Rheumatology. ${ }^{15}$ Nonosteoarthritic femoral condylar cartilages were collected at autopsy from 17 individuals of different ages (17 to 70 years).

\section{Peptide Synthesis}

The peptide chosen for the preparation of the immunogen corresponds to the primary C-terminal neoepitope (C2K) generated in triple-helical human Col II by the pro-

\begin{tabular}{|c|c|c|}
\hline $\begin{array}{r}\text { Type II } \\
\text { Alpha } 1 \text { Chain }\end{array}$ & \multicolumn{2}{|c|}{\begin{tabular}{l}
\multicolumn{6}{c}{ Cathepsin K cleavage site } \\
$\qquad$ \\
E A G K K P G K A G E R G P P G
\end{tabular}} \\
\hline $\begin{array}{r}\text { Immunizing and } \\
\text { assay peptide }\end{array}$ & $C$ G E A G K P G & \\
\hline Competing Peptides & 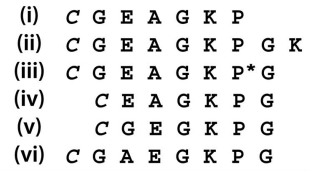 & \\
\hline
\end{tabular}

Figure 1. Sequences of the collagen $\alpha_{1}$ (II) chain in the region of the cathepsin K cleavage site and the synthetic peptides used in the antisera preparation and characterization. A cysteine residue (italics) was added to the $\mathrm{N}$ terminus for coupling to the carrier protein. $\mathrm{P}^{*}$ denotes 4-hydroxyproline. teolytic action of cathepsin K (Figure 1). ${ }^{9}$ For the determination of the specificity of the anti-neoepitope antiserum, six other peptides were synthesized: a one-residue truncation (Figure 1, i) and a one-residue extension (Figure 1, ii) of the immunizing peptide at the $\mathrm{C}$ terminus and a sequence similar to that of the immunizing peptide, except for the proline residue that was 4-hydroxylated (Figure 1, iii). In addition, three other peptides were prepared to investigate the importance of the $\mathrm{N}$-terminal portion of the epitope. These included deletion of either the $\mathrm{G}$ (Figure 1, iv) or A (Figure 1, v) or inversion of the AE dipeptide (Figure 1, vi). A cysteine residue was added to the common $\mathrm{N}$ terminus of each peptide to allow conjugation of the sulfhydryl group to the carrier proteins, ovalbumin and keyhole limpet hemocyanin. The peptides were synthesized at the Sheldon Biotechnology Centre, McGill University, or by CanPeptide Inc. (Pointe-Claire, Canada).

\section{Production of Polyclonal Antibodies}

The synthetic peptide corresponding to C2K neoepitope was coupled to keyhole limpet hemocyanin and the protein content was determined as previously described. ${ }^{16}$ The conjugate was used to immunize four young, disease-free, New Zealand White rabbits (female, 2.5 to 3.0 $\mathrm{kg}$ ) (Veterinary School, University of Montreal, Ste-Hyacinthe, Canada). Preimmune bleeds were obtained before immunization for use as control serum. Each rabbit was immunized on day 0 intramuscularly with a total of $0.5 \mathrm{mg}$ of antigen emulsified with complete Freund's adjuvant. On days 14 and 28 the rabbits were boosted with similar quantities of keyhole limpet hemocyanin-conjugated peptide in Freund's incomplete adjuvant. On day 38 the rabbits were exsanguinated by cardiac puncture and serum was collected.

\section{Characterization of Antisera Titer and Specificity}

A direct enzyme-linked immunosorbent assay (ELISA) assay was used to determine the antibody titer. The antiserum with the highest titer was selected for use. Investigation of the neoepitope specificity of the antiserum was performed by competitive inhibition ELISA as described. ${ }^{17}$ The percentage binding and percentage inhibition were calculated for each of the standard peptides and results were expressed on a molar basis.

\section{Inhibition ELISA for Analyses of Col II Neoepitope Produced by Cathepsin K Cleavage}

Immulon-2 plates (VWR International, Montreal, Canada) were coated with the peptide-ovalbumin conjugate (prepared as described above for the hemocyanin conjugate) diluted in phosphate-buffered saline (PBS), $\mathrm{pH} 7.2$, at $3 \mathrm{ng} / \mathrm{well}(50 \mu \mathrm{l} / \mathrm{well})$, the optimum concentration as determined by checkerboard analyses. After overnight incubation at $4^{\circ} \mathrm{C}$, the plate was washed three times with PBS-0.1\% Tween 20 and blocked with $100 \mu$ l of PBS-1\% 
bovine serum albumin (BSA), at room temperature for 30 minutes. Serial dilutions of the standard peptide containing the epitope that had been used for immunization were prepared and added at $50 \mu \mathrm{l} /$ well in triplicate to roundbottom polypropylene plates used as preincubation plates; the antiserum was diluted 1:12,000 (optimum dilution as determined by checkerboard analyses) in PBS-1\% BSA, 0.1\% Tween 20, pH 7.2, and added to the plates (50 $\mu$ l/well). In the nonspecific binding wells $50 \mu \mathrm{l}$ of PBS- $1 \%$ BSA and $50 \mu$ of PBS- $1 \%$ BSA, $0.1 \%$ Tween were added; the maximum binding wells contained $50 \mu \mathrm{l}$ of the diluted antiserum and $50 \mu \mathrm{l}$ of PBS-1\% BSA. After a 1-hour incubation at $37^{\circ} \mathrm{C}, 50 \mu \mathrm{l}$ of each preincubated well was transferred to the Immulon-2 flat-bottom, 96-well microtiter plates. The plates were incubated at $4^{\circ} \mathrm{C}$ for 30 minutes and then washed three times with PBS-0.1\% Tween 20. Alkaline phosphatase-conjugated goat antirabbit IgG (Sigma, St. Louis, MO), diluted 1:1000 in PBS-1\% BSA, 0.1\% Tween20 was then added to each well $(50 \mu / / w e l l)$. The plate was incubated for 1 hour at $37^{\circ} \mathrm{C}$, washed three times with PBS- $0.1 \%$ Tween 20 , and once with distilled water. One 5-mg tablet of alkaline phosphatase substrate (Sigma) was dissolved in $10 \mathrm{ml}$

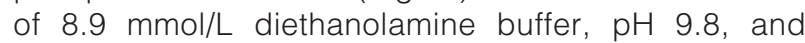
added to the plate $(50 \mu \mathrm{l} /$ well). The optical density (405 $\mathrm{nm}$ ) was read after a 1-hour incubation. The detection limit of the newly developed assay was $2.8 \mathrm{ng} / \mathrm{ml}$ and the coefficients of variation $(\% \mathrm{CV})$ of the intra-assays and interassays were $<10 \%$. The analytic recovery was 87.2 to $97.3 \%$ and the recovery rates for the serial dilution were 92 to $108 \%$.

\section{Digestion of Human Col II with Cathepsin K, MMP-13, and MMP-3}

Recombinant human procathepsin $\mathrm{K}$ was expressed in the Pichia pastoris, processed to the mature form and purified as described previously. ${ }^{18} \mathrm{Col}$ II was dissolved in $0.2 \mathrm{~mol} / \mathrm{L}$ acetic acid $(2 \mathrm{mg} / \mathrm{ml})$ and dialyzed at $4^{\circ} \mathrm{C}$ against $50 \mathrm{mmol} / \mathrm{L}$ sodium acetate buffer, $\mathrm{pH}$ 5.5, containing $2 \mathrm{mmol} / \mathrm{L}$ dithiothreitol, $2 \mathrm{mmol} / \mathrm{L}$ ethylenediaminetetraacetic acid, and $350 \mathrm{mmol} / \mathrm{L} \mathrm{NaCl} .^{9}$ The digestion buffer had the same composition as the dialyzing buffer with the addition of $0.15 \%(\mathrm{w} / \mathrm{v})$ chondroitin-4 sulfate (chondroitin sulfate A, Sigma). To observe the effect of increasing the enzyme concentration on the reaction rate, the first digestion was performed by using four different concentrations of cathepsin $\mathrm{K}(1,3,10$, and $30 \mu \mathrm{mol} / \mathrm{L})$ throughout a single digestion time course of 3 hours at room temperature $\left(25^{\circ} \mathrm{C}\right)$. The reaction was stopped by the addition of a specific cysteine protease inhibitor, E-64 (Peptide International, Louisville, KY), at a final concentration of $50 \mu \mathrm{mol} / \mathrm{L}$. Two other digestions were per-

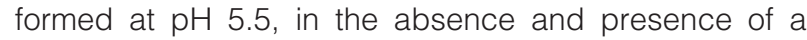
potent and selective nonbasic cathepsin $\mathrm{K}$ inhibitor, ${ }^{19}$ L-873724 (Merck Frosst, Kirkland, Canada). Digestions at $\mathrm{pH} 7.0$ in the presence of $2 \mu \mathrm{mol} / \mathrm{L}$ cathepsin $\mathrm{K}$ were used to determine the time-dependent release of the epitope at $0,3,24$, and 48 hours, in the absence or presence of chondroitin-4 sulfate or chondroitin-6 sulfate (chondroitin sulfate C, Sigma). The generation of the neoepitope was assessed by using the inhibition ELISA described above. The digestion of human Col II with MMP $-13^{2}$ was performed to determine whether that MMP-13, thought to be the dominant collagenase involved in Col II degradation in OA cartilage, can generate the neoepitope produced by cathepsin K. The ELISA assay was used to measure the generation of C2K neoepitope. The $\mathrm{C} 2 \mathrm{C}$ assay ${ }^{20}$ was used to demonstrate the collagenase activity of MMP-13. In addition, heat denatured Col II was digested overnight with 4-aminophenylmercuric acetate-activated MMP-3 (Triple Point Biologics, Forest Grove, OR). ${ }^{21}$ The activity of the enzyme was demonstrated by sodium dodecyl sulfate-polyacrylamide gel electrophoresis and the ELISA assay was used to assess possible generation of C2K neoepitope.

\section{Digestion of Normal Articular Cartilage with Cathepsin K}

The generation and release of C2K neoepitope from the tissue was first assessed in vitro by incubating normal articular cartilage with cathepsin $\mathrm{K}$. Thus, $60 \mathrm{mg}$ of cartilage was sliced into cubes of $2 \times 2 \mathrm{~mm}^{2}$ and incubated in $2 \mathrm{ml}$ of digestion buffer described above, without the addition of chondroitin sulfate ( $\mathrm{pH} 7$ ), containing $2 \mu \mathrm{mol} / \mathrm{L}$ of cathepsin K. The same conditions were used for the control, except that no enzyme was added. The incubation was performed at $25^{\circ} \mathrm{C}$ with shaking and buffer aliquots were removed at $0,0.5,1,2,3$, and 6 hours. Degradation of Col II and proteoglycan by cathepsin K was assessed by inhibition ELISA of C2K neoepitope and a modified colorimetric 1,9-di-methylmethylene blue (DMMB) dye-binding assay to detect glycosaminoglycan (GAG) release, respectively. ${ }^{22}$ Matrix molecule release into the buffer was expressed per mg weight of cartilage as pmol $\mathrm{C} 2 \mathrm{~K}$ and $\mu \mathrm{g} \mathrm{GAG}$.

\section{Collagen Extraction from Articular Cartilage}

The content of $\mathrm{C} 2 \mathrm{~K}$ and $\mathrm{C} 2 \mathrm{C}$ neoepitopes in cartilage were determined by extraction with $\alpha$-chymotrypsin (Sigma). This degrades denatured but not intact triple helical collagen, to solubilize the collagen neoepitopes that can then be assayed. Femoral condylar cartilages from 17 normal and 19 OA individuals were washed and digested with $\alpha$-chymotrypsin, as previously described. ${ }^{23}$ The digest was removed and stored at $-20^{\circ} \mathrm{C}$ until analyzed. To ensure that the cathepsin K-generated neoepitope is not cleaved by $\alpha$-chymotrypsin, a separate digestion was first performed by treating a 50-ng/ml immunizing peptide solution with $\alpha$-chymotrypsin as described above. No loss of epitope was observed. The concentration of the neoepitope released from the cartilage in the $\alpha$-chymotrypsin digests was expressed as pmol of neoepitope/mg wet wt of cartilage (based on the molecular weights of the two neoepitope sequences used as standards in the ELISA assays: 717.8 Da for the C2K neoepitope and 972 Da for $\mathrm{C} 2 \mathrm{C})$. 


\section{Explant Culture of OA Cartilage in the Presence and Absence of the Cathepsin K Inhibitor} L-873724

Femoral condylar cartilages from eight OA patients were prepared and cultured as previously described. ${ }^{24}$ Under these culture conditions explant viability was always preserved for the duration of the culture as revealed by progressive incorporation of radiolabeled amino acids over and above frozen and thawed controls (data not shown). Wet weights of 70 to $80 \mathrm{mg}$ were placed in each of the wells of the culture plates (24-well Costar 3548 plate; Corning Inc., Corning, NY). After 48 hours of preculture at $37^{\circ} \mathrm{C}$ the media were changed (day 0) and then replaced every 4 days for a total of 16 days. The cultures were established in quadruplicate with and without the cathepsin $\mathrm{K}$ inhibitor $(\mathrm{L}-873724)^{19}$ at $10 \mathrm{nmol} / \mathrm{L}, 25$ $\mathrm{nmol} / \mathrm{L}$, and $50 \mathrm{nmol} / \mathrm{L}$ in a final concentration of $0.1 \%$ dimethyl sulfoxide. These concentrations are based on inhibition data for tissue studies supplied by our collaborator at Merck. At present we have no idea of the concentration of cathepsin $\mathrm{K}$ in these tissues. The inhibitor was added fresh to the medium at each change. The media collected from day 4 to day 16 and the recovered cartilage were stored at $-20^{\circ} \mathrm{C}$ until analysis after digestion with $\alpha$-chymotrypsin. Complete digestion of the cartilage was ensured by further adding $1 \mathrm{ml} /$ tube of $1 \mathrm{mg} / \mathrm{ml}$ proteinase $\mathrm{K}$ (Sigma) in $50 \mathrm{mmol} / \mathrm{L}$ Tris- $\mathrm{HCl}$ containing the proteinase inhibitors. ${ }^{2}$ After overnight incubation at $56^{\circ} \mathrm{C}$ no residue remained and the enzyme was inactivated by boiling the samples for 10 minutes. The proteinase $\mathrm{K}$ digests were used only for determination of residual cartilage GAG content. Separate studies revealed that proteinase $\mathrm{K}$ degrades the $\mathrm{C} 2 \mathrm{~K}$ neoepitope. The media and $\alpha$-chymotrypsin digests were assayed by ELISA for the C2K neoepitope. The concentration of the neoepitope released from the cartilage was calculated by summation of the concentrations found both in the media and $\alpha$-chymotrypsin digests and expressed as pmol of $\mathrm{C} 2 \mathrm{~K} / \mathrm{mg}$ wet wt of cartilage as above. The media, $\alpha$-chymotrypsin and proteinase $\mathrm{K}$ digests were assayed by the DMMB assay as described above. GAG release into the media was expressed as a percentage of the total GAG that represents the summation of the GAG concentration present in the media and the one from the two cartilage extracts.

\section{Toxicity Analyses}

The effect of L-873724 on the synthesis of Col II and other matrix proteins was assessed by measuring the incorporation of $\left[{ }^{3} \mathrm{H}\right]$ proline in cartilage culture. The tissue was maintained for 7 days as described above, in the presence and absence of the inhibitor at $10 \mathrm{nmol} / \mathrm{L}, 25$ $\mathrm{nmol} / \mathrm{L}$, and $50 \mathrm{nmol} / \mathrm{L}$ and media were changed at days 4 and 7 . On day 7, medium was supplemented with 25 $\mu \mathrm{Ci} / \mathrm{ml}$ of tritiated proline (Amersham, Buckinghamshire, UK) and culture continued for 48 hours. After culture, the cartilage was harvested and washed three times for 10 to 15 minutes in PBS to remove free label. The cartilage was digested with proteinase $\mathrm{K}$ as described above and radioactivity determined by scintillation counting.

\section{Statistical Analysis}

Spearman rank correlations were used for analyzing the relationship between the amount of neoepitopes generated in articular cartilage by collagenases and cathepsin K. Mann-Whitney U-tests were used to compare the nonarthritic and OA groups, in terms of neoepitope contents detected by immunoassay. The difference between the median of neoepitope concentration in treated and nontreated samples in the inhibitor study was also determined by Mann-Whitney analysis.

\section{Results}

\section{Direct-Binding ELISA for Determination of Antibody Titers}

One primary and two booster immunizations with the peptide conjugate yielded specific antisera with titers from $1: 8 \times 10^{5}$ to $1: 1 \times 10^{6}$ in each of four rabbits, as detected by direct ELISA. A single serum of the highest titer (R771) was selected for further study. The optimum dilution of the antiserum to be used in the immunoassay, determined by checkerboard analysis was $1: 12,000{ }^{2}$

\section{Inhibition ELISA for Neoepitope Characterization}

A standard inhibition curve was created by using a range of concentrations of the nonconjugated immunizing peptide. Six other inhibition curves were created using the other synthetic peptides to assess specificity (Figure 2). The antibody has high affinity for the immunizing peptide used alone as a competitive antigen in the ELISA inhibition assay, giving a median inhibitory concentration (IC50) of $45 \mathrm{nmol} / \mathrm{L}$. The binding of the antibody to the competing synthetic peptides (truncated/extended forms of the immunizing peptides) (i and ii) was negligible showing that removal or addition of residues at the $\mathrm{C}$ terminus resulted in a loss of inhibition as previously observed for the antibody $\mathrm{C} 2 \mathrm{C} .{ }^{20}$ The antibody showed reduced affinity for the form of the peptide containing hydroxyproline (peptide iii, Figure 2A). Although the antibody has some affinity for the N-terminally truncated peptide (iv), negligible binding to competing peptides containing deletion of the alanine residue (v) or where the glutamic acid and alanine residues were inverted (vi) demonstrated the importance of the $\mathrm{N}$ terminal region segment of the neoepitope (Figure 2B). With these findings in mind it is important to point out that the neoepitope sequence EAGKPG is unique for $\mathrm{Col}$ II based on a BLAST search. ${ }^{25}$

\section{Digestion of Human Col II with Cathepsin K, MMP-13, and MMP-3}

To further validate the specificity of the antibody to the neoepitope, Col II digested with increasing concentra- 


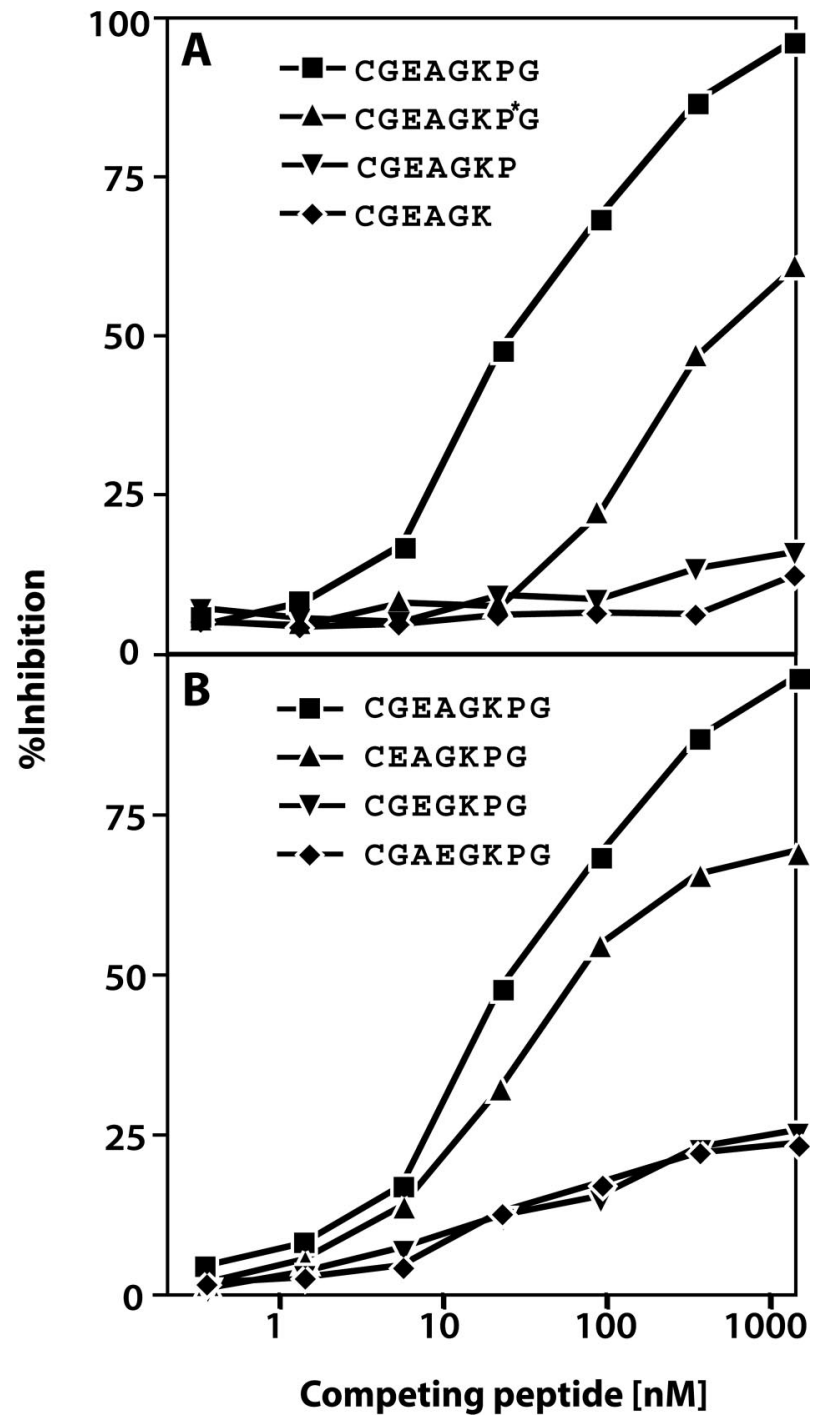

Figure 2. Immunoassay standard curve and epitope specificity of the antiserum R771. Percent inhibition obtained with serial dilutions of the immunizing and competing peptides with amino acid addition or deletion at the carboxy terminus (A) or modification of the amino terminus (B).

tions of cathepsin $\mathrm{K}$ was analyzed after 3 hours of incubation by competitive inhibition ELISA (Figure 3). Although there was negligible reactivity with uncleaved Col II, with increasing concentrations of cathepsin $\mathrm{K}$, an increase in the generation of neoepitope was detected, reaching a peak at $10 \mu \mathrm{mol} / \mathrm{L}$ followed by a decrease at $30 \mu \mathrm{mol} / \mathrm{L}$. This suggests that higher concentrations of enzyme degrade the neoepitope because of gelatinolytic activity. To investigate the effect of $\mathrm{pH}$, the time-dependent release of the neoepitope in the presence of a constant amount of enzyme at pH 5.5 and 7.0 was assessed. At pH 5.5, considered the optimum $\mathrm{pH}$ of cathepsin $K,{ }^{13}$ a rapid increase in the release of the neoepitope with a peak at 3 hours and a significant drop at 48 hours was observed, again suggesting that the neoepitope can be further degraded by the enzyme. When the specific cathepsin K inhibitor (L-873724) was added to the digestion buffer at the start of the incubation, the release of the neoepitope at each of the subsequent time

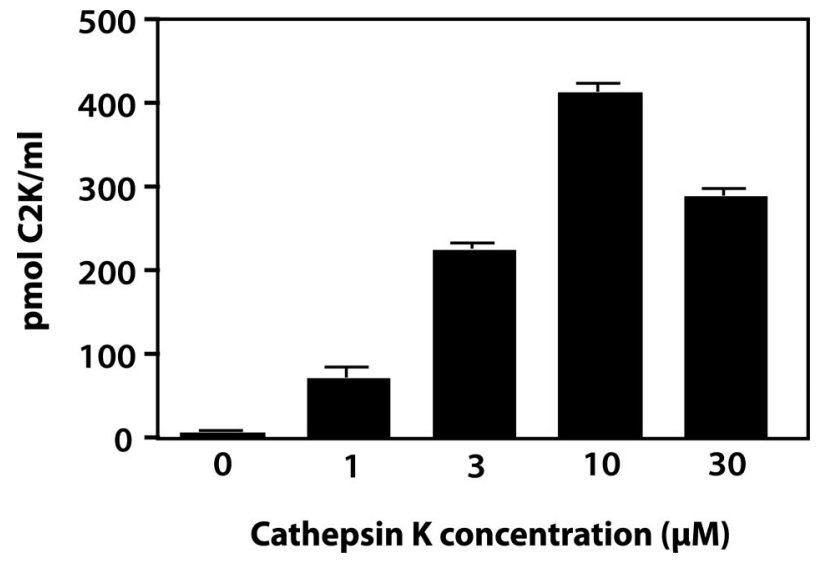

Figure 3. Concentration-dependent generation of $\mathrm{C} 2 \mathrm{~K}$ neoepitope by cathepsin K. Human Col II $(0.6 \mathrm{mg} / \mathrm{ml})$ was digested for 3 hours with various concentrations of cathepsin K. Neoepitope was measured by competitive ELISA.

points was negligible. At $\mathrm{pH} 7.0$ the release of the neoepitope was much slower and only reached a maximum at 24 to 48 hours (Figure 4). When digestion was performed in the absence of chondroitin sulfate (CS) at $\mathrm{pH}$ 7.0 a decreased release of neoepitope was detected. The addition of C4S or C6S to the digestion buffer significantly increased the amount of $\mathrm{C} 2 \mathrm{~K}$ neoepitope, reaching a peak at 48 hours (Figure 5). These findings suggest that chondroitin sulfate increases the activity and stability of the enzyme, as previously described. ${ }^{10}$ Cathepsin $\mathrm{K}$ did not generate the C2C neoepitope, as shown by analysis of collagen digests with $\mathrm{C} 2 \mathrm{C}$ assay (data not shown). Moreover, the C2K neoepitope was not detected when

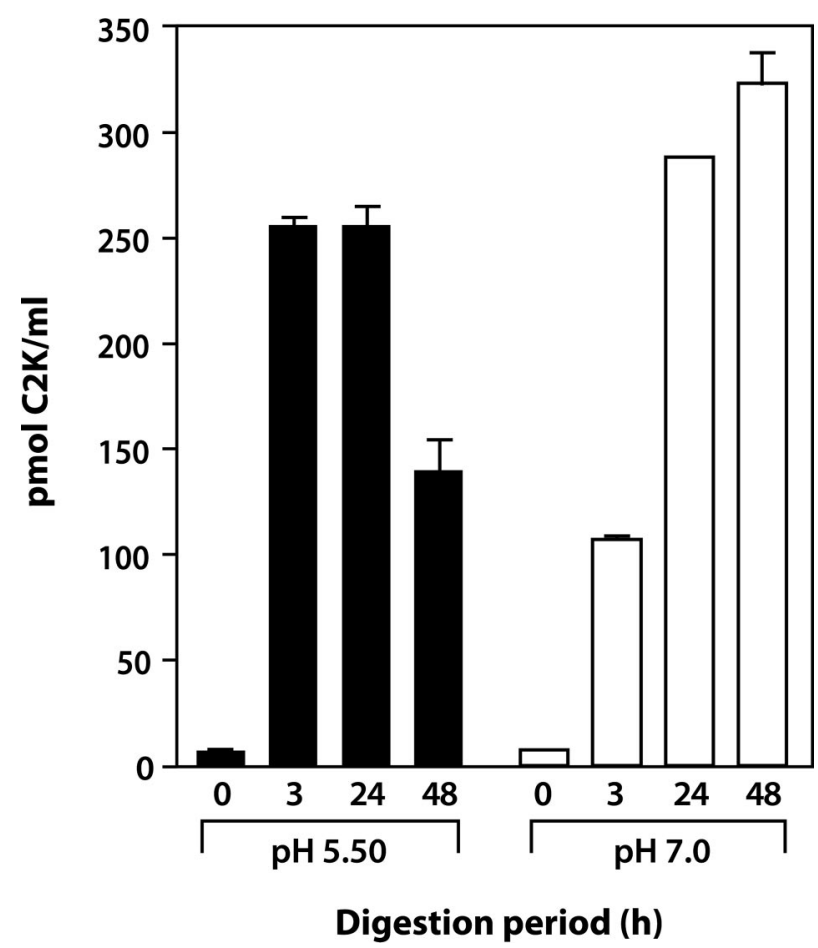

Figure 4. Time courses of cleavage of triple helical human Col II by cathep$\sin \mathrm{K}$ at $\mathrm{pH} 5.5$ and $\mathrm{pH}$ 7.0. The generation of the $\mathrm{C} 2 \mathrm{~K}$ neoepitope was measured by competitive ELISA. 


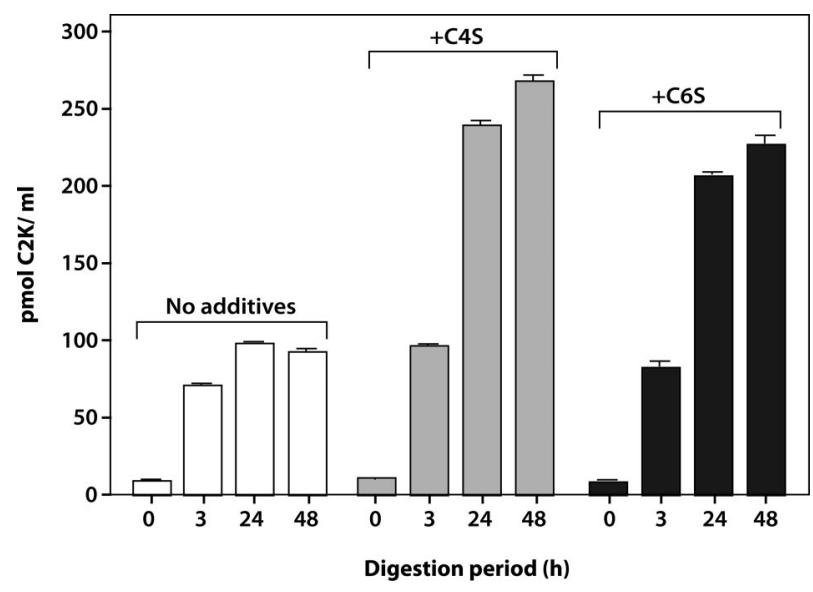

Figure 5. Effect of chondroitin sulfate on cathepsin $\mathrm{K}$ activity with time Col II was digested with cathepsin $\mathrm{K}$ in the absence and presence of either chondroitin 4-sulfate (C4S) or chondroitin 6-sulfate (C6S), at $\mathrm{pH}$ 7.0. The generation of the cathepsin $\mathrm{K}$ neoepitope was measured by competitive ELISA.

collagen was digested by MMP-13 although digestion was confirmed by the C2C collagenase assay (data not shown). A review of peptide sequences known to be degraded by MMP $-3,{ }^{26}$ suggests the possibility that the C2K epitope could be generated by this protease after digestion of denatured Col II. However, when heat-denatured Col II was degraded with MMP-3 (full digestion being demonstrated by sodium dodecyl sulfate-polyacrylamide gel electrophoresis analysis) no C2K neoepitope was detected.

\section{Cathepsin K Can Digest Cartilage in Situ}

When cartilage was incubated with cathepsin $\mathrm{K}$ for 6 hours at $\mathrm{pH} 5.5$, increasing amounts of the C2K neoepitope and GAG were detected in the supernatant. The release of GAG was detected from time 0 showing that cathepsin $\mathrm{K}$ efficiently degrades proteoglycans from the moment it is added to the cartilage (Figure 6); time 0 was recorded after the enzyme was added to the digestion buffer containing the cartilage sample.

\section{Total Contents of Cathepsin K and} Collagenase-Generated Neoepitopes in Human Articular Cartilages

$\alpha$-Chymotrypsin extracts of denatured Col II from uncultured nonarthritic and OA cartilages were assayed for both cathepsin K- and collagenase-generated (C2C) neoepitope contents. These were both increased in content with aging but only significantly in the case of the cathepsin K neoepitope (Figure 7). In OA a significant increase was observed for both neoepitopes compared to adult articular cartilage. Strong positive and significant correlations were noted between cathepsin $\mathrm{K}$ and collagenase-generated neoepitope contents in nonarthritic cartilages $(r=0.7765, P=0.0002)$ and in OA cartilages $(r=0.5656, P=0.0115)$ (Figure 8$)$. The concentrations

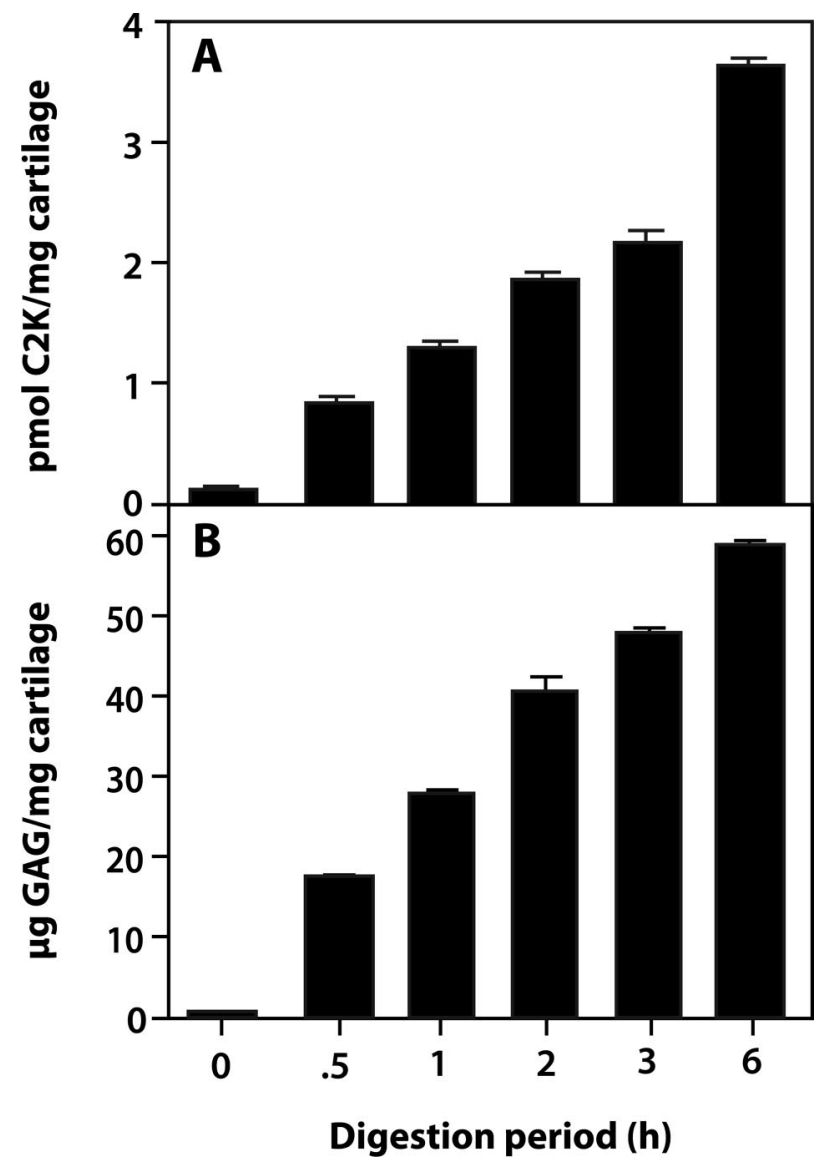

Figure 6. Digestion of normal articular human cartilage with cathepsin $\mathrm{K}$. The digestions were performed at $\mathrm{pH} 5.5$ and the release of $\mathrm{C} 2 \mathrm{~K}$ neoepitope (A) and GAG (B) throughout time was measured by competitive ELISA and the DMMB assay, respectively.

of the C2C neoepitope were usually two to three times higher than those of $\mathrm{C} 2 \mathrm{~K}$.

\section{OA Articular Cartilage Explants Cultured With and Without the Cathepsin K Inhibitor}

L-873724 is a selective inhibitor of human cathepsin $\mathrm{K}$ exhibiting an IC50 of $0.2 \mathrm{nmol} / \mathrm{L}$ against human cathepsin $\mathrm{K}$ and a 890-fold higher IC50 value versus cathepsin B, L, and $\mathrm{S}$. The inhibitor was used as a specific means of determining the involvement of this enzyme in the generation of the cathepsin $\mathrm{K}$ neoepitope. The inhibitor was found to be nontoxic in that it did not affect the incorporation of tritiated proline into newly synthesized proteins at a range of concentrations including those used in our studies (data not shown). The C2K neoepitope was hardly detectable in some of these cultures in the culture media being present mainly in cartilage. When these were totaled it was obvious that the inhibitor reduced the generation of the neoepitope in four of eight OA patients with a significant reduction being noted in three cases (Figure 9). In one case study (OA66) there was insufficient cartilage to use the inhibitor at $50 \mathrm{nmol} / \mathrm{L}$. The inhibitor had no effect on proteoglycan degradation measured as glycosaminoglycan release (data not shown). 


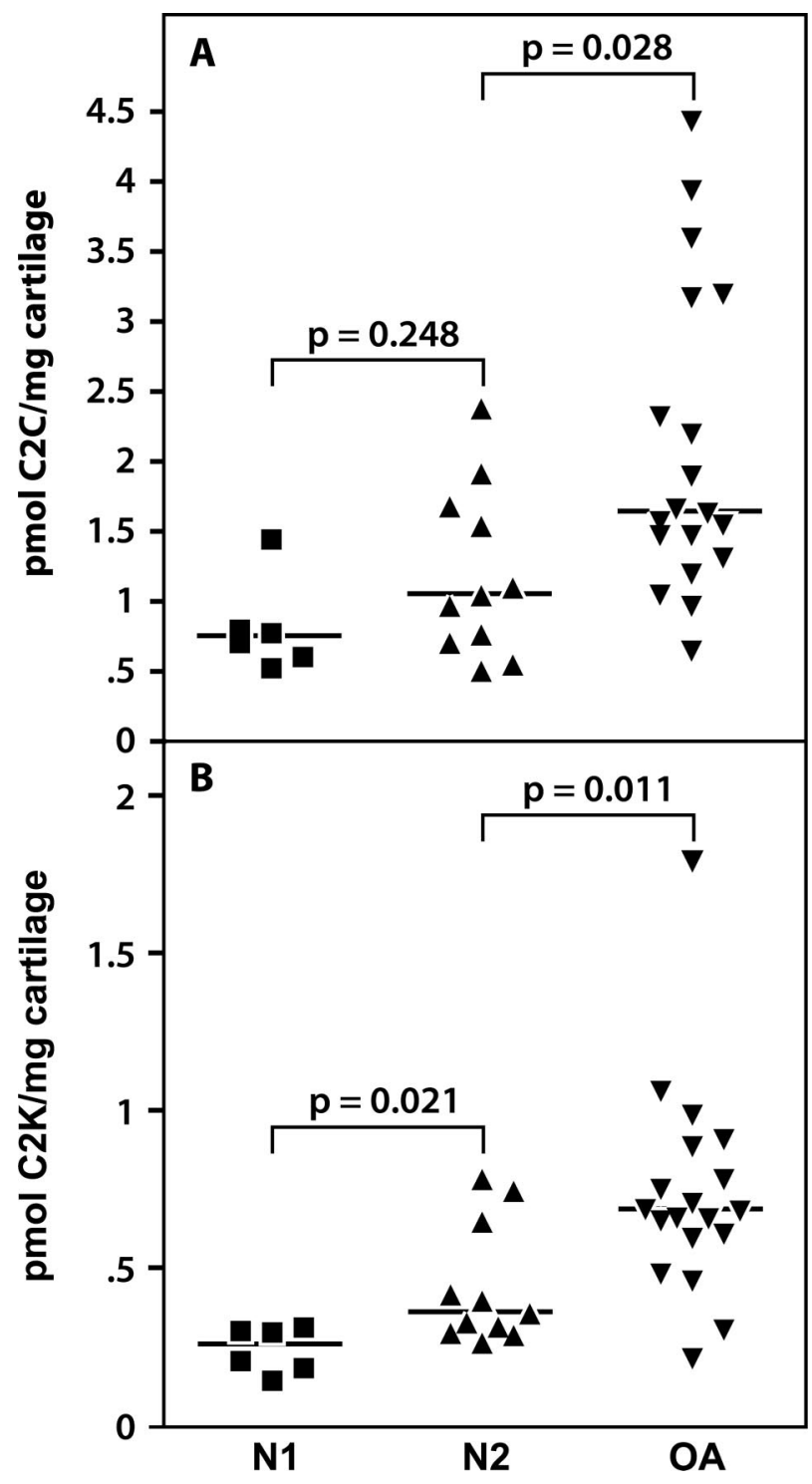

Figure 7. $\mathrm{C} 2 \mathrm{C}$ and $\mathrm{C} 2 \mathrm{~K}$ neoepitope contents in normal and $\mathrm{OA}$ articular cartilages. The cartilage was digested with $\alpha$-chymotrypsin and $\mathrm{C} 2 \mathrm{C}(\mathbf{A})$ and C2K (B) neoepitope levels were quantitated in the digests by competitive ELISAs. Nonarthritic cartilages were divided into two groups: N1 (patient ages, 15 to 38 years) and N2 (patient ages, 41 to 70 years); patient ages for OA cartilages ranged between 49 to 87 years. In both cases the difference between the median (bar) of neoepitope content in the nonarthritic and the OA cartilages was determined by Mann-Whitney analysis and the $P$ values are shown in the figures.

\section{Discussion}

Cathepsin K, a cysteine proteinase of the papain family, mediates the resorption of bone by osteoclasts ${ }^{13,27,28}$ and is considered a drug target for the treatment of osteoporosis in which bone resorption is excessive. This potentially very degradative enzyme is also expressed by other cells, including chondrocytes in articular cartilage. ${ }^{14}$ Collagenases of the MMP family have been thought to be the principal enzymes involved in the degradation of $\mathrm{Col} / \mathrm{I}$ under physiological conditions. Very little is known about the involvement of cathepsin $\mathrm{K}$ in the degradation of cartilage extracellular matrix under physiological and pathological conditions.
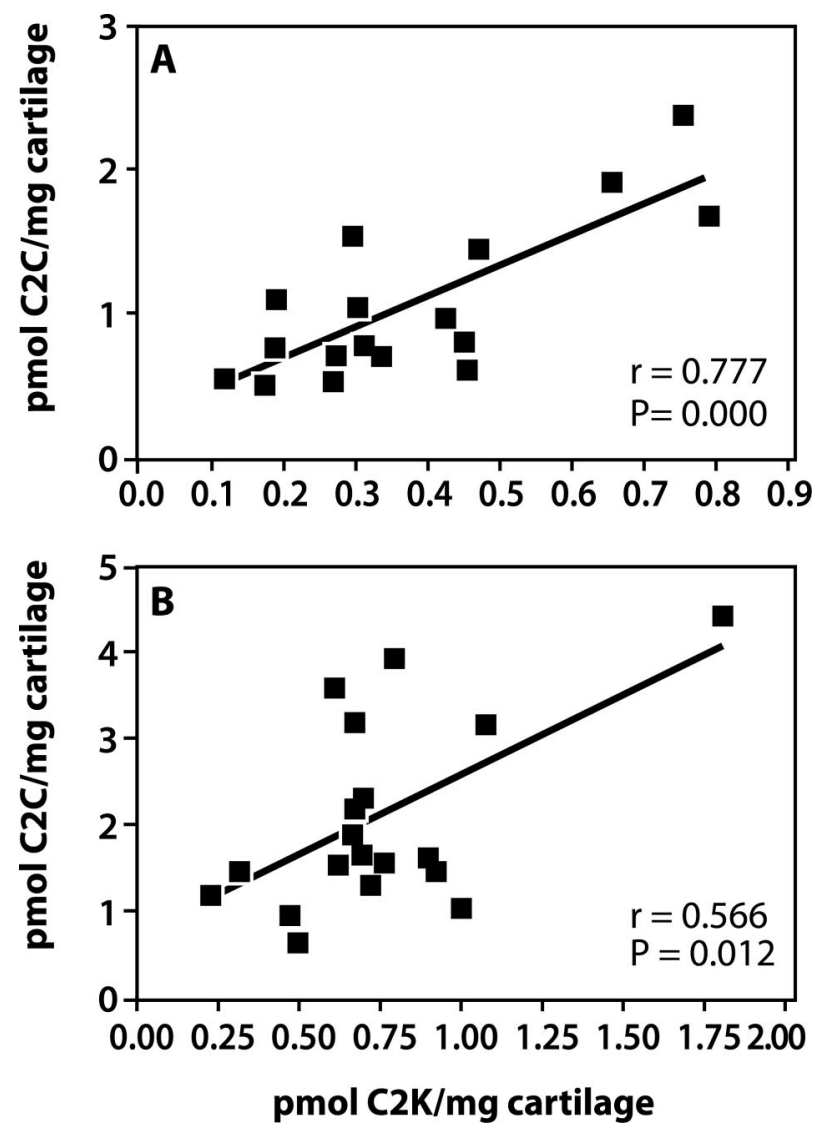

Figure 8. Correlations between the content of C2C (MMP collagenase-generated neoepitope) and $\mathrm{C} 2 \mathrm{~K}$ neoepitopes in articular cartilages. Data from Figure 7 were used to show the correlation between $\mathrm{C} 2 \mathrm{C}$ and $\mathrm{C} 2 \mathrm{~K}$ neoepitope content in nonarthritic (A) and OA (B) cartilages. Statistically significant relationships between the two neoepitope contents were determined by Spearman rank correlational analysis $(n, r$, and $P$ values are shown in the figure)

Expression of cathepsin $\mathrm{K}$ by chondrocytes is increased in $O A$ articular cartilage in direct relation to the severity of $\mathrm{OA} .{ }^{14}$ It was also observed that the $\mathrm{pH}$ of articular cartilage in $\mathrm{OA}$ decreases from neutral to a $\mathrm{pH}$ of $\sim 5.5$ in association with the progression of cartilage degradation, thus providing an optimal environment for cathepsin $\mathrm{K}$ activity. Our results confirm that cathepsin $\mathrm{K}$ is capable of cleaving $\mathrm{Col} \mathrm{II}$ at neutral $\mathrm{pH}$ in articular cartilage and that this activity is enhanced in the presence of chondroitin sulfate, a major component of articular cartilage. The presence of this GAG no doubt enhances the stability of the enzyme at this $\mathrm{pH}$ as shown earlier. ${ }^{29}$ The use of the cathepsin $\mathrm{K}$ inhibitor clearly revealed that the generation of the $\mathrm{C} 2 \mathrm{~K}$ neoepitope in $\mathrm{OA}$ articular cartilage involves the activity of cathepsin $\mathrm{K}$ in a number of OA cartilages from different patients, sufficient to stimulate our interest in the role of this protease in collagen cleavage in OA. But because inhibition was not always observed, as was the case in similar studies we made using an MMP-13 inhibitor, ${ }^{27}$ the question remains as to whether other proteinases generate this neoepitope, assuming that the tissue is penetrated by the inhibitor in each of these cultures. Generation of this neoepitope by MMPs is not indicated because this family of proteinases 

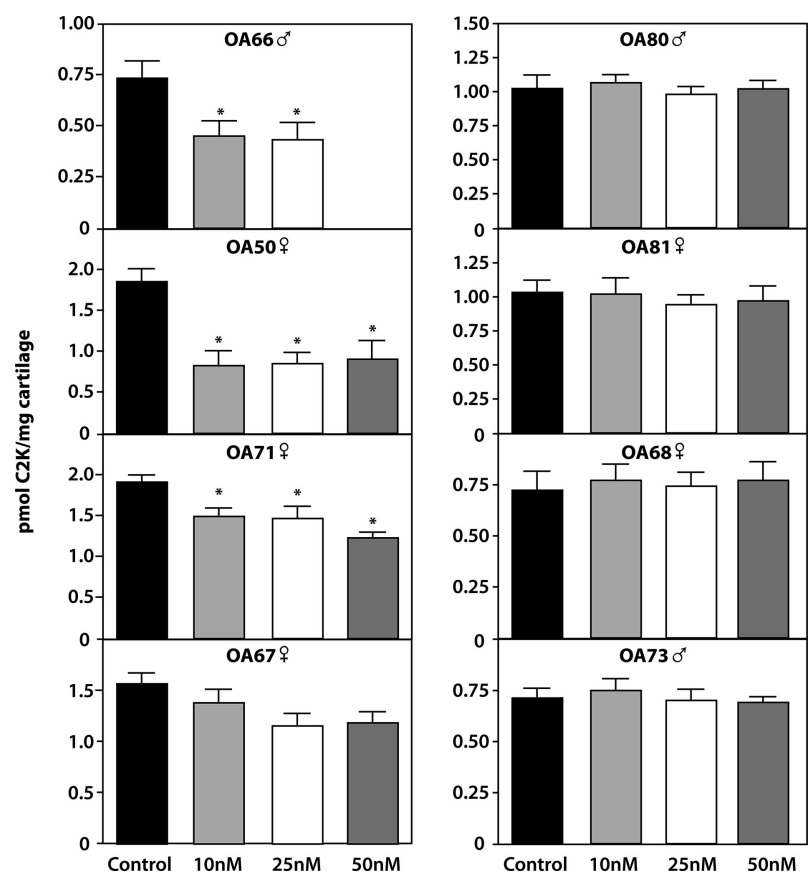

Figure 9. Reduction in the generation of $\mathrm{C} 2 \mathrm{~K}$ neoepitope by a specific cathepsin $\mathrm{K}$ inhibitor. OA explants from eight patients were cultured in the presence and absence of L-873724 inhibitor for 16 days. The content of the C2K neoepitope at the end of the culture was determined by competitive ELISA. The age and gender of each patient is indicated. $P$ values, determined by one-way analysis of variance test and less than 0.05 , are considered significant compared to control and are indicated (asterisk).

cleaves the collagen substrate with a proline residue at the $\mathrm{P} 3$ position rather than the $\mathrm{P} 2$ position as in the case for cathepsin K (information curated by the MEROPS database ${ }^{30}$ ). Thus only the cleavage of Col II by cathepsin $\mathrm{K}$ should be detected by this antineoepitope antibody. This conclusion is supported by our demonstration of the inability of MMP-3 to generate the cathepsin K neoepitope when it cleaves denatured Col II.

It is possible that the C2K neoepitope is not continuously generated and that a shift from more cathepsin $\mathrm{K}$ activity to MMP collagenase activity may occur with time. Thus, during the period of culture, cathepsin K may not have been active in the cases in which we observed no inhibition and that we measured C2K neoepitope that was already present and may have accumulated throughout time in the tissue and this masked detection of further neoepitope generated during culture. This may especially apply to cases in which the base levels of the neoepitope were higher. We considered the possibility of measuring cathepsin $\mathrm{K}$ levels immunologically but, because the protease could have been also present as both the proenzyme form and enzyme-inhibitor complexes, the measurements would not in any way reflect the levels of enzyme activity in the tissue. Clearly further detailed studies are required to examine this possibility and to compare cleavage of Col II by collagenases and other MMPs during this period by using collagenase and general MMP inhibitors. Our direct analytical data of OA cartilage suggest that there is cleavage of Col II by both MMPs and cathepsin K-like activity in the same tissue. But use of $\alpha$-chymotrypsin may also lead to activation of other molecules in cartilage, such as proteinases, the activities of which could influence neoepitope contents. So we must treat this as preliminary data.

Also it will be important to try and establish half-lives for these neoepitopes, something easier said than done in our experience. At present all we can say is that our data point to the involvement of cathepsin K-mediated cleavage of Col II in some patients. Whether the increase in aging also involves this cathepsin $\mathrm{K}$ also remains to be established. The close correlation between the amounts of neoepitopes generated by collagenases and cathepsin $\mathrm{K}$ in normal cartilages and less so in OA suggests that the activities of the proteases generating these neoepitopes are closely coordinated in health as in disease. As it stands the data suggest that there is more MMP collagenase activity. This remains to be confirmed. Further work also is required to investigate how cathep$\sin \mathrm{K}$ activity is regulated compared to that of the collagenases. The expression of collagenases in chondrocytes is known to be up-regulated by proinflammatory cytokines, such as interleukin-1 and tumor necrosis factor- $\alpha^{3,28}$ but little is known about the induction of cathep$\sin \mathrm{K}$ in chondrocytes. We are currently using the newly developed assay to assess the induction of Col II breakdown by cathepsin $\mathrm{K}$ in cultured bovine articular cartilage explants under the influence of different cytokines.

\section{Acknowledgments}

We thank Elisa de Miguel for peptide purification, Helene Richard for immunizations, Guylaine Bédard for the artwork, and Dr. Terrence Heathfield for the sodium dodecyl sulfate-polyacrylamide gel electrophoresis analysis.

\section{References}

1. Dodge GR, Poole AR: Immunohistochemical detection and immunochemical analysis of type II collagen degradation in human normal, rheumatoid and osteoarthritic articular cartilages and in explants of bovine articular cartilage cultured with interleukin 1. J Clin Invest 1989, 83:647-661

2. Billinghurst RC, Dahlberg L, Ionescu M, Reiner A, Bourne R, Rorabeck C, Mitchell P, Hambor J, Diekmann O, Tschesche H, Chen J, Van Wart H, Poole AR: Enhanced cleavage of type II collagen by collagenases in osteoarthritic articular cartilage. J Clin Invest 1997, 99:1534-1545

3. Mitchell PG, Magna HA, Reeves LM, Lopresti-Morrow LL, Yocum SA, Rosner PJ, Geoghegan KF, Hambor JE: Cloning, expression, and type II collagenolytic activity of matrix metalloproteinase-13 from human osteoarthritic cartilage. J Clin Invest 1996, 97:761-768

4. Dahlberg L, Billinghurst RC, Manner P, Nelson F, Webb G, Ionescu M, Reiner A, Tanzer M, Zukor D, Chen J, Van Wart HE, Poole AR: Selective enhancement of collagenase-mediated cleavage of resident type II collagen in cultured osteoarthritic cartilage and arrest with a synthetic inhibitor that spares collagenase 1 (matrix metalloproteinase 1). Arthritis Rheum 2000, 43:673-682

5. Hollander AP, Heathfield TF, Webber C, Iwata Y, Bourne R, Rorabeck C, Poole AR: Increased damage to type II collagen in osteoarthritic articular cartilage detected by a new immunoassay. J Clin Invest 1994, 93:1722-1732

6. Hollander AP, Pidoux I, Reiner A, Rorabeck C, Bourne R, Poole AR Damage to type II collagen in aging and osteoarthritis starts at the articular surface, originates around chondrocytes, and extends into 
the cartilage with progressive degeneration. J Clin Invest 1995, 96:2859-2869

7. Kempson GE: Relationship between the tensile properties of articular cartilage from the human knee and age. Ann Rheum Dis 1982, 41:508-511

8. Miller EJ, Harris ED Jr, Chung E, Finch JE Jr, McCroskery PA, Butler WT: Cleavage of type II and III collagens with mammalian collagenase: site of cleavage and primary structure at the $\mathrm{NH}_{2}-$ terminal portion of the smaller fragment released from both collagens. Biochemistry 1976, 15:787-792

9. Kafienah W, Brömme D, Buttle DJ, Croucher LJ, Hollander AP: Human cathepsin $\mathrm{K}$ cleaves native type I and II collagens at the $\mathrm{N}$ terminal end of the triple helix. Biochem J 1998, 331:727-732

10. Li Z, Hou WS, Brömme D: Collagenolytic activity of cathepsin K is specifically modulated by cartilage-resident chondroitin sulfates. Biochemistry 2000, 39:529-536

11. Hou WS, Li Z, Buttner FH, Bartnik E, Bromme D: Cleavage site specificity of cathepsin $\mathrm{K}$ toward cartilage proteoglycans and protease complex formation. Biol Chem 2003, 384:891-897

12. Garnero P, Borel O, Byrjalsen I, Ferreras M, Drake FH, McQueney MS, Foged NT, Delmas PD, Delaissé JM: The collagenolytic activity of cathepsin $\mathrm{K}$ is unique among mammalian proteinases. J Biol Chem 1998, 273:32347-32352

13. Brömme D, Okamoto K, Wang BB, Biroc S: Human cathepsin O2, a matrix protein-degrading cysteine protease expressed in osteoclasts. Functional expression of human cathepsin $\mathrm{O} 2$ in Spodoptera frugiperda and characterization of the enzyme. J Biol Chem 1996, 271:2126-2132

14. Konttinen YT, Mandelin J, Li TF, Salo J, Lassus J, Liljestrom M, Hukkanen M, Takagi M, Virtanen I, Santavirta S: Acidic cysteine endoproteinase cathepsin $\mathrm{K}$ in the degeneration of the superficial articular hyaline cartilage in osteoarthritis. Arthritis Rheum 2002, 46:953-960

15. Altman R, Asch E, Bloch D, Bole G, Borenstein D, Brandt K, Christy W, Cooke TD, Greenwald R, Hochberg M: Development of criteria for the classification and reporting of osteoarthritis. Classification of osteoarthritis of the knee. Diagnostic and Therapeutic Criteria Committee of the American Rheumatism Association. Arthritis Rheum 1986, 29:1039-1049

16. Billinghurst RC, Ionescu M, Poole AR: Immunoassay for collagenasemediated cleavage of types I and II collagens. Methods Mol Biol 2001, 151:457-472

17. Mort JS, Roughley PJ: Production of antibodies against degradative neoepitopes in aggrecan. Methods in Molecular Medicine, vol 100: Cartilage and Osteoarthritis, vol. 1: Cellular and Molecular Tools.
Edited by Sabatini M, Pastoureau P, De Ceuninck F. Totowa, Humana Press, 2004, pp 237-249

18. Billington CJ, Mason P, Magny M-C, Mort JS: The slow-binding inhibition of cathepsin $\mathrm{K}$ by its propeptide. Biochem Biophys Res Commun 2000, 276:924-929

19. Li CS, Deschenes D, Desmarais S, Falgueyret JP, Gauthier JY, Kimmel D, Léger S, Masse F, McGrath ME, McKay DJ, Percival MD, Riendeau D, Rodan SB, Thérien M, Truong V-L, Wesolowski G, Zamboni R, Black WC: Identification of a potent and selective non-basic cathepsin K inhibitor. Bioorg Med Chem Lett 2006, 16:1985-1989

20. Poole AR, lonescu M, Fitzcharles MA, Billinghurst RC: The assessment of cartilage degradation in vivo: development of an immunoassay for the measurement in body fluids of type II collagen cleaved by collagenases. J Immunol Methods 2004, 294:145-153

21. Gunja-Smith Z, Woessner JF Jr: Activation of cartilage stromelysin-1 at acid $\mathrm{pH}$ and its relation to enzyme $\mathrm{pH}$ optimum and osteoarthritis. Agents Actions 1993, 40:228-231

22. Farndale RW, Buttle DJ, Barrett AJ: Improved quantitation and discrimination of sulphated glycosaminoglycans by use of dimethylmethylene blue. Biochim Biophys Acta 1986, 833:173-177

23. Billinghurst RC, Wu W, Ionescu M, Reiner A, Dahlberg L, Chen J, Van Wart H, Poole AR: Comparison of the degradation of type II collagen and proteoglycan in nasal and articular cartilages induced by interleukin-1 and the selective inhibition of type II collagen cleavage by collagenase. Arthritis Rheum 2000, 43:664-672

24. Kobayashi M, Squires GR, Mousa A, Tanzer M, Zukor DJ, Antoniou J, Feige U, Poole AR: Role of interleukin-1 and tumor necrosis factor alpha in matrix degradation of human osteoarthritic cartilage. Arthritis Rheum 2005, 52:128-135

25. Altschul SF, Gish W, Miller W, Myers EW, Lipman DJ: Basic local alignment search tool. J Mol Biol 1990, 215:403-410

26. Nagase $\mathrm{H}$, Fields GB: Human matrix metalloproteinase specificity studies using collagen sequence-based synthetic peptides. Biopolymers 1996, 40:399-416

27. Shi G-P, Chapman HA, Bhairi SM, DeLeeuw C, Reddy VY, Weiss SJ Molecular cloning of human cathepsin $\mathrm{O}$, a novel endoproteinase and homologue of rabbit OC2. FEBS Lett 1995, 357:129-134

28. Brömme D, Okamoto K: Human cathepsin O2, a novel cysteine protease highly expressed in osteoclastomas and ovary. Molecular cloning, sequencing and tissue distribution. Biol Chem Hoppe-Seyler 1995, 376:379-384

29. Li Z, Hou WS, Escalante-Torres CR, Gelb BD, Brömme D: Collagenase activity of cathepsin $\mathrm{K}$ depends on complex formation with chondroitin sulfate. J Biol Chem 2002, 277:28669-28676

30. Rawlings ND, Morton FR, Barrett AJ: MEROPS: the peptidase database. Nucleic Acids Res 2006, 34(Suppl 1):D270-D272 